\title{
How to set up an audit
}

\author{
Brian W Ellis
}

Accountability by surgeons for the work they undertake is now seen by health service management in the United Kingdom as a high priority. ${ }^{2}$ In December 1987 the Royal College of Surgeons made it clear that hospitals and their surgical training posts would not be recognised unless audit and exercises in quality control were performed regularly. These and other recent events, such as initiatives for managing resources, have sharply focused the need for accurate information on clinical activity.

Surgeons are increasingly prepared to undertake some form of clinical audit for reasons beside these external influences. They have been motivated by aspects of audit ranging from administrative efficiency ${ }^{3}$ to clinical quality control ${ }^{4}$ and possibly by a perception that data collected by a surgical team will be more accurate than those collected by medical records clerks. ${ }^{5}$ In an extreme case a firm was accused of being "unproductive" on the basis of erroneous data. ${ }^{6}$ They are probably also aware of some of the lessons that can be learnt from critical self audit. ${ }^{78}$

\section{Requirements for success}

Clinicians who decide to set up an audit must accept that time, effort, and finance are all essential to success. All members of a team must be determined to make the audit work. Hence there is a vital need for a senior member of the firm to coordinate his or her junior colleagues and instil a sense of purpose and enthusiasm for the project. The commonest causes of failure are lack of belief in the value of audit, lack of interest by junior and secretarial staff, and a notion that an expensive box of hardware and software will automatically provide all the answers. Those who have worked with computer systems in a medical environment will know that all users should perceive some tangible personal benefit from their efforts and that software must be robust, easy to use, and useful.

The demographic data are entered on to the system by the firm's secretary, who then has the advantage of immediate access to patients' details and can respond instantly to most telephone inquiries from patients and their general practitioners - a considerable benefit. I believe that the house surgeon should be responsible for collecting the clinical data and the registrar for entering them directly on to the computer; only then will the data be accepted as clinically correct. Delegating the entering of clinical data to a secretary is wholly inappropriate and often leads to inaccuracies. We have endorsed this view by having these tasks written into the relevant job descriptions. The advantages for the junior staff are instant access to information about patients and the offer of full reports of all operative experience and inpatient activity that took place during the tenure of their post. They also gain some computing experience in the process and use the software for other tasks such as literature searching and word processing, and the database for research, writing papers, and producing job applications. These prerequisites and a mechanism to "capture" clinical data encompass the human requirements of clinical audit.

\section{Hardware}

Proponents of a system based on punched cards highlight the advantages of speed, low cost, and simplicity of such an approach. To reap the full reward of the labour of collecting data, however, there can be little doubt that a computer based system offers the most flexible means of storing data, analysing them quickly, and producing reports. A computer based system may stand alone, be part of a network, or be a terminal from a hospital system. Though a system that permits integration of clinical data into a hospital information system is possible, experience has been limited and none have yet come close to matching the power and flexibility of custom designed software run on a dedicated microcomputer within a surgical department. Thus for the foreseeable future systems based on microcomputers present the best solution. The choice of hardware depends on whether the system is to be used on a single machine or in a network or multiuser environment. In the latter case a minimum requirement would be an IBM or IBM compatible computer running on an 80386 processor. Such a machine offers greater speed and can handle a concurrent operating system to provide multiple terminals. Terminals may also be linked through a modem over a telephone line.

A tape back up device is the fastest and most efficient form of backup and is more likely to be used than the multiple floppy disks necessary for an archive procedure. The printer should either be laser based, for the finest output and, usually, the quietest operation, or a heavy duty 24 pin dot matrix machine.

\section{Software}

Any software system designed for audit must fulfil several essential requirements. Given the regular turnover of junior staff and secretaries, it needs to be exceptionally easy to learn and use. It should also allow audit information to be collected as a byproduct of the daily activity in the surgical office. Thus a system should help with all the routine administrative tasks that a surgical secretary and members of the clinical team are faced with from day to day. Just as the data from a checkout point in a supermarket are used in stock control, the daily changes made, for example, to the waiting list should be logged to allow standard Körner reports on waiting list activity to be produced automatically.

Similarly, the entry of clinical data, which is an essential ingredient in composing and producing a discharge summary, inevitably generates a base of data from which comprehensive audit reports and analyses can be created. The system should also generate the appropriate codes (International Classification of Diseases and Office of Population Censuses and Surveys) for diagnoses and operations and allow reports to be produced for the medical records department.

We have used the "Micromed" system" for over four years and find that it meets these requirements. Uniquely, it is not constrained by being a variation of a commercial general purpose database. Other well
Brian W Ellis, FRCs,

BrMed F 1989;298:1635-7 


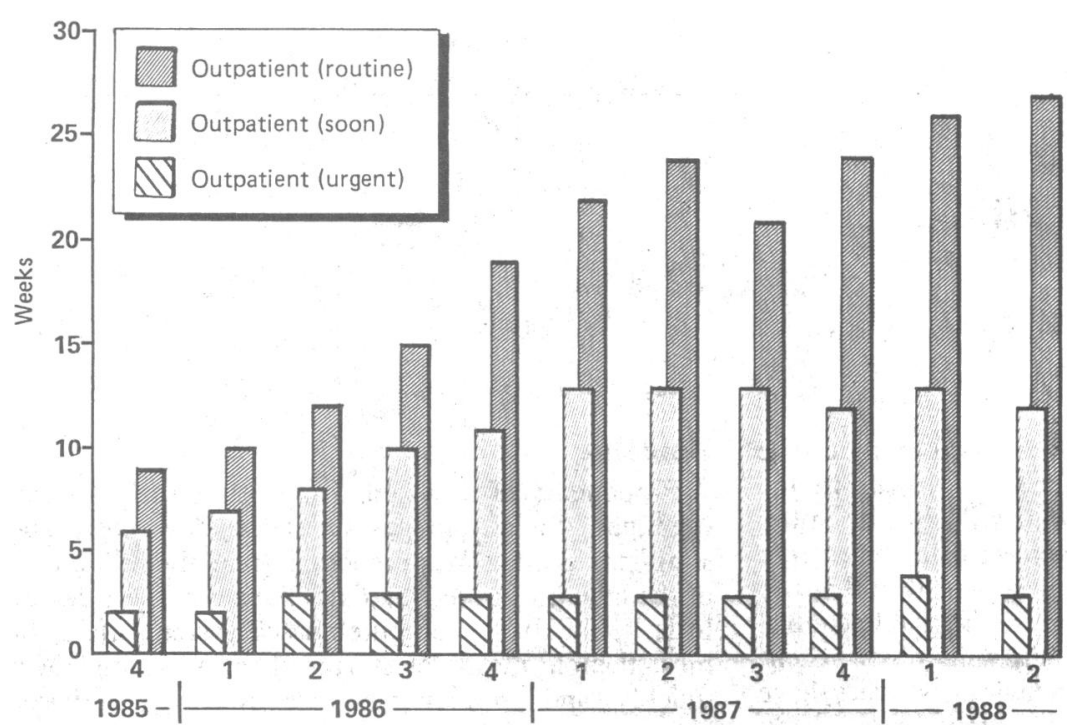

FIG 1-Mean delay to admission in weeks by priority in patients booked in the outpatient department established packages are available. ${ }^{10}$ Generally, software products that are widely used are more likely to be robust and free of "bugs."

\section{Data collection}

Although it may be possible to "audit" outpatient activity, the returns for considerable effort in collecting data are relatively small. This is not to minimise the importance of quality control in outpatient care but to emphasise that far more is to be gained by collecting inpatient data. When a patient is booked for admission his or her demographic data are recorded (usually with a sticky label) with details of the reason for admission, prority on the waiting list, and, if given, the dates for admission and operation.

There is no correct means of collecting the clinical data; the technique used must be tailored to the way the clinical office works and the discharge information is collected and processed. Although extracting data from clinical notes as they arrive in the office after a patient's discharge is possible, errors of omission resulting from case records not arriving will always occur. In our experience it is the notes of patients who die or are transferred to or from colleagues in the same or other hospitals that never turn up for a summary. Thus we keep a separate card with brief clinical details on every inpatient under our care. There is less of a problem with the notes of patients admitted electively if a waiting list module exists within the system to prompt for overdue clinical information.

If data collected for audit are to be of value they must be accurate. Checking and validating data are thus fundamentally important. For the past five years I have held a weekly meeting of my firm. All patients discharged in the preceding week are discussed, and the data that have been, or will be, entered on to the computer are checked. Although it forms a worthwhile teaching forum, the meeting is particularly valuable in checking proposed follow up for each patient. In the past data were not entered on to the computer until they had been checked. Now we validate the data that have been entered and amend any errors: this change has minimised delay in producing a discharge summary. We can then produce a report that includes all relevant information, which can be sent to the medical records department.

\section{Starting an audit}

The whole clinical team must be amply versed in the mechanism of collecting data well in advance of the date on which the computer system is introduced. The content of discharge documents and the frequency with which they are sent to the hospital medical records department should be planned with that department; in our case we send a weekly document. Special care is needed in entering hospital numbers. Given that these are likely to be a key field in the system and unique to a patient, they must always be entered the same way. To a computer the following are distinct: $\mathrm{AH} / 00341$; Ah.00341; AH341; AH-341, etc. Beware of the distinction between the letter $\mathrm{O}$ and a zero. The following rules help to avoid duplicate patient records:

- Use only capitals and never use capital O

- Do not use stops, commas, hyphens

- Expand numerical elements to the correct length with leading zeros.

The final ingredient for successfully inaugurating a system is training. Ideally this should start before and continue after the system is introduced so that inconsistencies in data handling may be ironed out early. New members of staff should also be given enough training and induction in the use of any system.

\section{Potential benefits}

What then do we gain from all this effort? There are those who believe that the measure of an efficient computer system is the saving of time and jobs. This may be the case when a system is instituted primarily to replace repetitive manual tasks. In the case of the surgical office, however, time is not saved but the pattern of work for the secretary changes: efficiency indubitably increases.

We now have instantaneous access to information that in the past would have been delayed by hours, days, or, in the case of hospital activity analysis, many months. We can extract information and generate reports in detail. A computerised audit and administration system also acts as a focus of information within the office and puts the consultant firmly in control of his or her clinical practice. Reports may be produced either in response to specific queries for management or research or as audit reports that are built into the system. An audit report analyses the work of the firm in considerable detail and in a standardised form that provides a sound basis for comparison with past performance or other units.

The interpretation of such a report in isolation can easily permit poor statistics to be rationalised. I believe that it is extremely important that surgeons are prepared to pool their data. This enables individual surgeons to compare their results with those of their colleagues. An inevitable spin off of such an exercise is the generation of norms for common procedures with

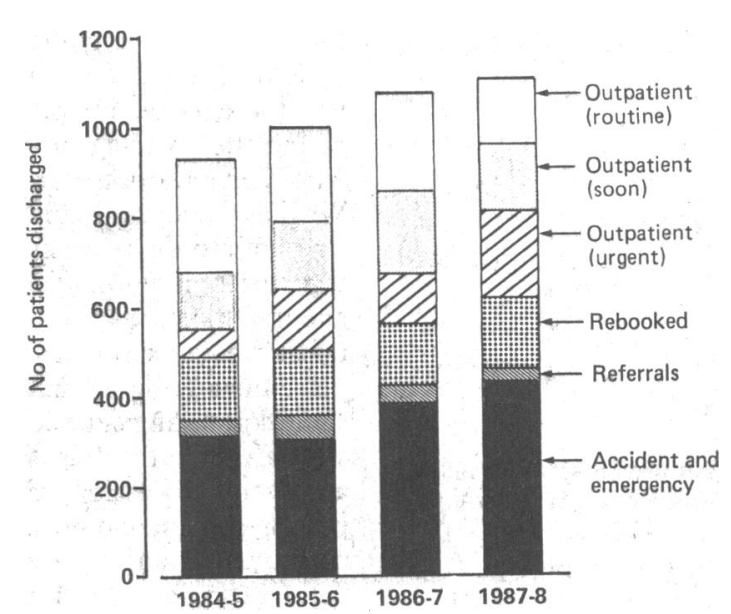

FIG 2-Discharges by source of patients over five years 
regard to preoperative and postoperative lengths of stay, rates of complications, mortality, and age and sex distributions. Access to such information also helps in simple tasks of resource management. We produced a histogram showing the lengthening waiting list that had led to increasing delays, especially for patients waiting for routine operations (fig 1). Another histogram (fig 2) showed that turnover had increased: we decided that we were approaching an operational ceiling, constrained by theatre time and available beds. Clearly the increasing number of admissions from the accident and emergency department had impaired turnover for elective operations. By modelling data extracted from the system we showed that a modest reduction in the accident and emergency workload would allow a large increase in the turnover of elective cases through fewer beds and with reduced cost but with an increased demand for theatre time.

\section{The future}

We are approaching the time when there can be few excuses for surgeons who do not take a critical look at their results. We already have pressure from health service management and the college; I would suggest that patients should expect the same from us as well. I believe that we will hear more of regional norms and that these may be used to judge performance of individual doctors. I am concerned that management will try to modify mixture of cases to improve overall performance. Reducing the number of high risk, expensive or long stay operations, simply in the name of surgical efficiency is clearly unacceptable. It is, however, administrative prudence to be able to identify such groups to seek ways of improving care without increasing costs.

I Warden J. All for audit now. Br Med f 1988;297:1569.

2 Maynard A. Who will die and who will survive? Health Service fournal 1988;98:247.

3 Wyllie JH, Kidson IG, Wyllie DH. Pursuing efficiency in surgical practice. Br Med f 1988;297:1368-71.

4 Ellis BW. Clinical audit. Brf Hosp Med 1988;39:187.

5 Whates PD, Birzgalis AR, Irving M. The accuracy of hospital activity analysis hates PD, Birzgalis AR, Irving M.
codes. Br Med f 1982;284:1857-8.

6 Skinner PW, Riley D, Thomas EM. The use and abuse of performance indicators. BrMed f 1988;297:1256-9.

7 Gruer R, Gordon DS, Gunn AA, Ruckley CV. Audit of surgical audit. Lancet 1986; ; :23-6.

8 Gough MH, Kettlewell MGW, Marks CG, Holmes J. Audit: an annual assessment of the work and performance of a surgical firm in a regional teaching hospital. Br Med f 1980;281:913-8.

9 Ellis BW, Michie HR, Esufali ST, Pyper RJD, Dudley HAF. Development of a microcomputer based system for surgical audit and patient administration. IR Soc Med 1986;80:157-61.

10 Dunn DC, Dale RF. Combined computer generated discharge documents and surgical audit. $\mathrm{Br} \mathrm{Med} \mathcal{F}$ 1986;292:816-8.

\section{BOOKS RECEIVED}

\section{Accident and emergency}

On Call: Principles and Protocols. J H Gillies, S A Marshall, J Ruedy. (P xxi+330; figs; 12.95 paperback. Philadelphia: Saunders, 1989. ISBN 0-7216-2576-2.

\section{Acquired immune deficiency} syndrome

Color Atlas of AIDS. A E Friedman Kien. (Pp xvi+155; figs and colour plates; £25.) Philadelphia: Saunders. 1989. Distributed by Harcourt Brace Jovanovich. ISBN 0-7216-2759-5. The Gilobal Impact of AIDS. Ed A F Fleming, M Carballo, D FitzSimons, et al. (Pp xxxi+427; fig $\$ 29.50$ paperback.) New York: Liss, 1988. Distributed by John Wiley and Sons. ISBN 0-8451-4271-2.

\section{Addiction}

Drugs und British Societv: Responses to a Social Problem in the Eighties. Ed S MacGregor. (Pp xi +224; 99.95 paperback.) London: Routledge, 198 ISBN 0-115-01752-1.

\section{Alternative medicine}

Holistic Reflixologv. A Grinberg. IPp 304; figs; £20.) Wellingborough: Thorsons, 1989. ISBN 0-7225-1612-

Homoeoputhy Reconsidered: a NecoLook t Hahnemunn's Organon. A M Clower. Pp 122; £10.95.) London: Gollanc\% 1989. ISBN 0-575-04+58-6.

New Wavs to Health. "A Guide to Acupuncture." P Firebrace, S Hill. (Pp 160; figs; colour plates; $1+95$ paperback. London: Hamlyn, 1989. ISBN 0-600-5601 t7.

Neri Ways to Health. "A Guide to Chiropractic." S Moore. (Pp 160) figs; colour plates; $\mathfrak{f} 4.95$ paperback. London: Hamlyn, 1989. ISBN 0-600) $56016-3$

New" Ways to Health. "A Guide to Homeopathy:" S Richardson. IP 160; figs: colour plates; $\{4.95$ paper160; figs: colour plates; $1+.95$ paper-
back. L London: Hamlvn, 1989. ISBN back. London:

Anaesthesia

Anaesthesiu. Ed W S Nimmo, (; Smith. (Pp xiii +1496; indexes; figs; E95 two volume set.) Oxford: Black well Scientific, 1989. ISBN 0-63202257 t.

\section{Cardiology}

Cardioz'ascular Clincs. "Coronary Angioplasty. "Ed S Goldherg. Editor in chief A N Brest. (Pp xix +285; figs; C42.71. Philadelphia: Davis, 1989 ISBN 0-8036-4162-1.

\section{Cerebrovascular disorders}

Frontiers of Clinical Neuroscience. Vol 5. "Noninvasive Imaging of Cèrebrovascular Disease." Ed J Weinberger Series editors I Bodis-Wollner, E A Zimmerman. (Pp ix + 193; figs; colour plates; \$62.50.) New York: Liss, 1988. Distributed by John Wiley and Sons. ISBN 0-8451-4504-5.

\section{Communicable diseases}

Tuberculosis Control as an Integral Part of Primast Health Care. World Health Organisation. ( $\mathrm{Pp} 47$; $\mathrm{Sw}$ frs 9 paperOrganisation. (Pp 47; Sw frs 9 paperisation, 1988. ISBN 92+154241-6.

\section{Community medicine}

Moving Towards Hèalth: Annual Report 1988 Central Birmingham. Health Authority. (Pp $v+59$; figs; 16.95 paperback including postage and packing.) Obtainable from CBHA, Department of Community Medicine, District Office, Vincent Drive, Edgbaston, Birmingham B15 2 $\mathrm{TZ}$.

The New I'ublic Health: the Liverpool Experience. J Ashton, $\mathrm{H}$ Sevmour. (Pp viii + 184; figs; 99.95 paperback. Milton Kevnes: Open Univers Press, 1988. ISBN 0-335 15550-2.

\section{Dentistry}

Guidelines for Self Care in Oral Health. World Health Organisation. (Pp iit 70; figs; paperback, free of charge. Copenhagen: World Health Organisation, 1988. Obtainable from Oral Health Unit, WHO Regional Office for Europe, Scherfigsvej 8, DK-2100 Copenhagen 0 , Denmark.

Disabled/handicapped people

The Educution of People with Profound Multiple Handicaps; Resource Materials for Staff Training J Sebba. $\mathrm{Ppx}+160$; figs; f16.95 paperback.) Manchester
Manchester University Press, 1989 in association with the British Institute of Mental Handicap. ISBN 0-71902596-6.

Letting Go: Dilemmas for Parents Whose Son or Daughter has a Mental Handicap. A Richardson, J Ritchie. (Pp x +96 f6.95 paperback.) Milton Keynes: Open University Press, 1989. ISBN 0-335-15840-4.

\section{Endocrinology}

Endocrine System: Clinical Algorithms. Articles published in the British Medical foumal. (Pp viii $+52 ; 66.95$, overseas $£ 8(\$ 15)$ paperback, including postage, airmail overseas. BMA members $£ 6.45$, overseas $£ 7.50$ ( $\$ 14$ including postage.) London: British Medical foumal, 1989. ISBN 0-72790237-7.

\section{Environmental and public healt}

Sources, Effects and Risks of Ionizing Radiation. 1988 Report to the General Assembly by the United Nations Scientific Committee on the Effects of Atomic Radiation. ( $P p$ 647; paperAtomic Radiation. (Pp 647; paper-
back, price not stated.) New York: back, price not stated.) New York:
United Nations, 1988. Sales No. E.88.IX 7. ISBN 92-1-142143-8.

\section{Epidemiology}

Atlas of Disease Distributions: Analyti Approahces to Epidemiological Data. A D Cliff, $P$ Haggett. (Pp xv + 300; figs £75. Oxford: Basil Blackwell, 1989 ISBN 0-631-13149-3.

Causal Relationships in medicine: Practical System for Critical Appraisal. J $M$ Elwood. Pp xi+332; $\{30$. Oxford University Press, 1988. ISBN 0-19-261703-6.

Forensic Medicine

Forensic Medicine - a Handbook for Professionals. A A Watson. (Pp xiv + 331; figs; f14.95.) Aldershot: Gower. 1989. ISBN 0-566-05513-9.

\section{Gastroenterology}

Your Gut Feelings: a Complete Guide to Liaing Better with Intestinal Problems. H D Janowitz. Pp xiv +204 ; figs (12.95.) New York: Oxford University Press, 1989. ISBN 0-19217772-9.

\section{General medicine}

Textbook of Internal Medicine. Ed V T DeVita Jr, H L Dupont, E D Harris $\mathrm{Jr}$, et al. Editor-in-Chief W N Kelley. Pp xlviii +2679+index; figs and colour plates; $\$ 49.50$.) London: Lippincott, 1989. Distributed by Harper and Row. ISBN 0-39750795-X.

\section{Genetics}

Medical Genetics Handbook. H Chen. Pp xii +384 ; figs; paperback, price not stated.) St Louis: Green, 1988. ISBN 0-87527-371-8.

\section{Geriatrics}

Physiological Basis of Geriatrics. P S Timiras. (Pp x+467; figs; £45.) New Timiras. (Pp x+467; figs; £45.) New 420810-8.

\section{Health care issues}

Health, Prevention and Economics. D R Cohen, J B Henderson. (Pp vii +175; figs; £22.) Oxford: Oxford University Press, 1988. ISBN 0-19-261778-8

Quality Assurance Programme. KFC88/ 69. "Health Service Accreditation - an International Overview." I Sketris. (Ppiv $+64 ;\{4$.50 paperback.) London King's Fund Centre for Health Services Development, 1988.

The Supervision of Health Personnel at District Level. D Flahault, M Piot, A Franklin. (Pp iii + 100; figs; Sw frs 18 paperback.) Geneva: World Health Organisation, 1988. ISBN 92-4 154229-2.

\section{Miscellaneous}

Images in the Fire. $\mathrm{T}$ Whitehead. (Pp 118; figs; $£ 4.95$ paperback.) This book was produced to raise funds for social amenities to improve the quality of life of people with mental health problems. Available from Brighton Department of Psychiatry of the Elderly, Brighton General Hospital, Brighton BN2 3EN ISBN 0-9513341-0-7.

The India I Knew: Experiences of a Canadian Orthopaedic Surgeon Over 50 Canadian Orthopaedic Surgeon Over 50
Years. W J Virgin. (Pp 176; colour Years. W J Virgin. (Pp 176; colour
plates; paperback, price not stated.) plates; paperback, price not stated.)
1988. A vailable from W J Virgin MD, FRCS (Ed) (C), 43 Wellesley Street E, FRCS (Ed) (C), 43 Wellesley Street E, Suite 325 ,

Living Capsule. A S Withanage (Pp 